\title{
Neonatal seizures and outcome in a NICU of a tertiary care hospital of Andhra Pradesh-an two year study
}

\author{
Punith Patak Nagaram*, Pratima Piduru, Venkata Krishna Munagal
}

Department of Paediatrics, Narayana Medical College, Andhra Pradesh, India

Received: 28 February 2017

Accepted: 28 March 2017

\section{*Correspondence: \\ Dr. Punith Patak Nagaram, \\ E-mail: punithpatak@gmail.com}

Copyright: ( $)$ the author(s), publisher and licensee Medip Academy. This is an open-access article distributed under the terms of the Creative Commons Attribution Non-Commercial License, which permits unrestricted non-commercial use, distribution, and reproduction in any medium, provided the original work is properly cited.

\begin{abstract}
Background: Seizures are the most frequent clinical manifestation of central nervous system dysfunction in the newborn with the incidence varying from $1-5 \%$. Neonatal seizures often signal an underlying ominous neurological condition, most commonly hypoxia-ischemia, and others include stroke, intraventricular hemorrhage or intraparenchymal hemorrhage, meningitis, sepsis, and metabolic disorders. Neonatal seizures can permanently disrupt neuronal development, induce synaptic reorganization, alter plasticity and "prime" the brain to increased damage from seizures later in life. The present study was undertaken to delineate the various aspects of neonatal seizures, with special reference to etiology, clinical spectrum, and outcome in the Neonatal Intensive Care Unit (NICU) of a tertiary care Hospital.

Methods: A prospective cross sectional study was conducted in an NICU of a tertiary care hospital with 65 neonates in the study group for a period of 2 years. Gestational age assessment is done by modified Ballard's scoring system and detailed neurological assessment was done. Antenatal history of mother, demographic data, and clinical history of neonate was noted and evaluated. Laboratory investigations were done and results noted and outcome was recorded.

Results: Subtle seizure was the commonest $(40 \%)$ clinical seizures in our study followed by tonic $(21.5 \%)$. Tonic seizures were common in preterm and in full term subtle seizures. Babies with myoclonic seizures had $100 \%$ mortality. Hypoxic ischemic encephalopathy was the commonest cause (41.5\%) of mortality in our study. The worst outcome was with CNS malformation (50\%). A total of 10 deaths were recorded (15.4\%) with maximum association in cases with history of onset 7 days $(100 \%)$

Conclusions: Neonatal seizures are common and may be the first manifestation of neurological dysfunction after a variety of insults. Seizures may interfere with cardio-respiratory function and nutrition and may have detrimental effects on cerebral development. Global cerebral hypoxia-ischemia is the most common etiology of neonatal seizures, followed by intracranial bleed, hypoglycemia, septicemia, hypocalcemia, BE, CNS malformations.
\end{abstract}

Keywords: Ballard's scoring system, Hypoxic ischemia, Myoclonic seizures, Neonatal seizures

\section{INTRODUCTION}

Seizures are the most frequent clinical manifestation of central nervous system dysfunction in the newborn with the incidence varying from $1-5 \% .{ }^{1}$ Neonates are at higher risk for seizures compared to older children due to immaturity of the brain. ${ }^{2,3}$ Neonatal seizures are poorly classified, under-recognized, and often difficult to treat. Neonatal seizures often signal an underlying ominous neurological condition, most commonly hypoxia- ischemia, and others include stroke, intraventricular hemorrhage or intraparenchymal hemorrhage, meningitis, sepsis, and metabolic disorders. Neonatal seizures can permanently disrupt neuronal development, induce synaptic reorganization, alter plasticity and "prime" the brain to increased damage from seizures later in life. ${ }^{4}$

Recent advances in diagnostic technology have provided important insights into neonatal seizures. Techniques such as bedside video-electroenchephalogram (EEG) 
monitoring and MRI have challenged earlier beliefs and raised fundamental questions regarding the diagnosis, etiology and management of seizures in the newborn infant. These advances have further highlighted the essential differences between the seizures in the newborn infants and older patients including their response to conventional anticonvulsant agents. Neonatal seizures are powerful predictors of long-term cognitive and development impairment. ${ }^{5,6}$

The present study was undertaken to delineate the various aspects of neonatal seizures, with special reference to etiology, clinical spectrum, and outcome in the Neonatal Intensive Care Unit (NICU) of a tertiary care Hospital.

\section{METHODS}

A prospective cross sectional study was conducted in NICU of Narayana medical college and hospital, a tertiary care hospital for a period of two years from March 2014 to February 2016. The guardians of the neonate (Mother /father) were informed of the study and particulars of the details taken in the study. A written consent was obtained from the parents of the participants in the study. The study was approved by the college ethical committee.

A total of 65 neonates admitted with clinically manifested seizures hospitalized in the NICU during 2-year study period formed the study population. A structured questionnaire sheet containing the particulars of the antenatal history, demographic data, and clinical history of neonate was noted and evaluated as per NICU protocol. Gestational age assessment is done by modified Ballard's scoring system and detailed neurological assessment was done during NICU stay. Laboratory investigations like blood sugar, serum calcium was routinely done and CBC, CSF study, serum electrolytes, neurosonographic evaluation and other investigations (Blood culture, CT, MRI etc.) were done as and when indicated. The outcome of the neonate was recorded as death or discharge from the NICU. All the data was entered in Microsoft excel work sheet and analyzed statistically.

\section{Inclusion criteria}

Babies with neonatal seizures admitted to NICU (Neonatal Intensive Care Unit) attached to the Neonatology Division of Narayana Medical College and Hospital, formed the subjects.

\section{Exclusion criteria}

Infants were excluded if they had congenital abnormalities including dysmorphism or a major anomaly of a single organ, congenital viral infections, cranial birth trauma.

\section{RESULTS}

Amongst clinical types of seizures observed in our study population, the most common type was subtle seizures (40\%), subsequently tonic $(21.5 \%)$, multifocal clonic (20\%), focal clonic $(9.2 \%)$, clonic $(7.7 \%)$ and least common type was myoclonic seizures (1.6\%). In our study, subtle $(39.1 \%)$ and tonic $(60.9 \%)$ type of seizures is very common in preterm, and in full term subtle (40.5\%), focal clinic (14.3\%), multifocal clonic (13\%) and clonic $(11.9 \%)$ are common and rare type is myoclonic seizure (2.4\%). Babies with myoclonic seizures had $100 \%$ mortality, followed by focal clonic (33.3\%), multifocal clonic (23\%) and tonic seizure $(21.4 \%)$ and least subtle seizure (3.8\%) (Table 1).

Table 1: Type of seizures and relation to gestational age and their outcome.

\begin{tabular}{|ll|llll|}
\hline Types of seizure & No. $(\%)$ & Gestational age & Outcome & No. of cases & Deaths no. $(\%)$ \\
\hline Clonic & $5(7.7)$ & - & $5(11.9)$ & 5 & - \\
\hline Focal Clonic & $6(9.2)$ & - & $6(14.3)$ & 6 & $2(33.3)$ \\
\hline Multi Focal Clonic & $13(20)$ & - & $13(13.0)$ & 13 & $3(23.1)$ \\
\hline Myoclonic & $1(1.6)$ & - & $1(2.4)$ & 1 & $1(100)$ \\
\hline Subtle & $26(40)$ & $9(39.1)$ & $17(40.5)$ & 26 & $1(3.8)$ \\
\hline Tonic & $14(21.5)$ & $14(60.9)$ & - & 14 & $3(21.4)$ \\
\hline Total & 65 & $23(100)$ & $42(100)$ & 65 & $10(15.4)$ \\
\hline
\end{tabular}

Most common cause of neonatal seizures in our study group was hypoxic ischemic encephalopathy (41.5\%) followed by hypoglycemia $(13.87 \%)$, Intracranial bleed $(10.8 \%)$, septicemia $(10.8 \%)$, hypocalcemia $(7.7 \%)$, bilirubin encephalopathy $(6.1 \%)$, meningitis $(4.6 \%)$, $\mathrm{CNS}+\mathrm{M}$ (3.1) and the least was MAS+MA (1.6\%).
Association between HIE seizure revealed that seizures occur most often in stage II HIE $(81.5 \%)$, less often in stage III HIE (18.5\%). The worst outcome was with CNS malformation $(50 \%)$ followed by intracranial bleed $(42.9 \%)$, Bilirubin encephalopathy $(25 \%)$, septicemia $(28.6 \%)$, and the least was $(7.4 \%)$ in HIE (Table 2). 
Table 2: Etiology of seizures and their outcome.

\begin{tabular}{|lll|}
\hline Etiology & $\begin{array}{l}\text { No. of neonates } \\
(\%)\end{array}$ & $\begin{array}{l}\text { Deaths n } \\
(\%)\end{array}$ \\
\hline $\begin{array}{l}\text { Hypoxic Ischaemic } \\
\text { Encephalopathy(HIE) }\end{array}$ & $27(41.5)$ & $2(7.4)$ \\
\hline Hypocalcemia & $5(7.7)$ & - \\
\hline Hypoglycemia & $9(13.8)$ & - \\
\hline IC bleed & $7(10.8)$ & $3(42.9)$ \\
\hline Meningitis & $3(4.60$ & - \\
\hline Septicemia & $7(10.8)$ & $2(28.6)$ \\
\hline $\begin{array}{l}\text { Bilirubin } \\
\text { Encephalopathy }\end{array}$ & $4(6.1)$ & $1(25.0)$ \\
\hline CNS+Malformation & $2(3.1)$ & $1(50.0)$ \\
\hline Hypernatremia & $1(1.6)$ & $1(100)$ \\
\hline Total & $\mathbf{6 5}$ & $\mathbf{1 0}$ \\
\hline
\end{tabular}

In our study, a total of 10 deaths were recorded (15.4\%) with maximum association in cases with history of onset 7 days (100\%) followed by $<12 \mathrm{hrs}$ with $18.2 \%, 14.3 \%$ in cases with $24-48 \mathrm{hrs}$, and $12.2 \%$ in cases with 2-6 days. No deaths were recorded with history of $12-24 \mathrm{hrs}$. (Table 3).

Table 3: Outcome in relation to time of onset of seizure.

\begin{tabular}{|lll|}
\hline Onset of seizure & No. of cases & $\begin{array}{l}\text { Outcome } \\
\text { Deaths n }(\%)\end{array}$ \\
\hline$<12 \mathrm{hrs}$ & 11 & $2(18.2)$ \\
\hline $12-24 \mathrm{hrs}$ & 13 & - \\
\hline $24-48 \mathrm{hrs}$ & 14 & $2(14.3)$ \\
\hline $2-6$ days & 24 & $3(12.5)$ \\
\hline 7 days & 3 & $3(100)$ \\
\hline Total & 65 & $10(15.4)$ \\
\hline
\end{tabular}

\section{DISCUSSION}

Neonatal seizures form an important cause of NICU admission. Neonatal seizures are due to various causes like HIE, hypocalcemia, hypoglycemia, intracranial bleed, meningitis, septicemia, bilirubin encephalopathy and CNS malformations. This study evaluated etiologic and risk factors affecting outcomes in newborns with neonatal seizures and etiologic pattern of neonatal seizures in tertiary-care settings as also the outcome in relation to the type of seizure, etiology in relation to type of seizures, various etiologies of neonatal seizures, outcome in relation to etiology of seizures, types of seizure in relation to gestational age, immediate outcome (mortality) in relation to time of onset of seizures and seizures in different stages of HIE.

There were four recognizable clinical seizure types, subtle, clonic, tonic, and myoclonic, each of these types can be focal, multifocal or generalized. In the present study, subtle seizures 26/65 (40\%) were the most common type of seizures observed and the least common was myoclonic $1(1.6 \%)$ which coincides with the findings of Volpe et al who reported subtle (54\%) seizures, to be the commonest type, Scher et al subtle seizures (71\%) and Amith Upadhyay et al reported 50\% subtle seizures in their study. ${ }^{7-9}$

Seizure characteristics associated with adverse outcome are generalized myoclonic or tonic seizures, intractable seizures and burst suppression or persistent low voltage EEG states. In the present study, death was noticed in 1 case of subtle seizures (3.8\%), Focal clonic 2 cases $(33.3 \%)$, multifocal clonic 3 cases $(23.1 \%)$, tonic seizures 3 cases $(21.4 \%)$ and Myoclonic 1 cases $(100 \%)$ with no death in clonic seizures. Mizrahi and kellaway ${ }^{10}$ in their study observed, clonic - abnormal 4 (28.6\%) no death, myoclonic-abnormal $6(35.3 \%)$ death $5(29.4 \%)$, tonic abnormal 7 (53.8) death $3(23.1 \%)$, subtle (54.5\%) death $4(18.2 \%)$.

In the present study, subtle seizures were observed in many of the etiological states like HIE 12 (46.2\%), hypocalcemia 3 (11.5\%), hypoglycemia 5 (19.2\%), meningitis $1(3.8 \%)$, septicemia $1(3.8 \%)$, bilirubin encephalopathy $2(7.7 \%)$ followed by tonic seizures hypoglycemia $5(28.6 \%)$, intra cranial bleed $3(21.4 \%)$, septicemia $2(14.3 \%)$.

In a study by Mizrahi and kellaway, observed that in HIE related seizures- clonic 1 (7.1\%), myoclonic $11(64.7 \%)$, tonic $7(53.8 \%)$ and subtle $12(54.5 \%) .{ }^{10}$ In infections clonic $3(20.4 \%)$, tonic $5(22.7 \%)$ and subtle $5(22.7 \%)$. In Intra cerebral hemorrhage related seizures - clonic 3 (20.4\%), myoclonic $6(59.1 \%)$, subtle 1 (4.5\%). In Hypoglycemia related seizures-clonic 1 (7.1\%), myoclonic $1(5.9 \%)$. In CNS malformations-clonic 1 (7.1\%), myoclonic $2(11.8 \%)$.

HIE was the most common cause of neonatal seizures in our study contributing to $41.5 \%$, followed by hypoglycemia (13.8\%), IC bleed (10.8\%), septicemia (10.8\%), hypocalcemia (7.7\%), Bilirubin encephalopathy $(6.1 \%)$, meningitis $(4.6 \%)$ and CNS malformations $(3.1 \%)$ which are on par with observations of Mizrahi et al, David Evan's and Malcolm Levene in their studies. ${ }^{12,13}$ In a study by Rose and Lombroso of 137 cases, Hypocalcemia 28 (20.4\%), CNS malformations 13 (9.5\%), hypoglycemia $7(5.1 \%)$ and congenital malformations of CNS $11(8.0 \%)$ were the cause of seizures which is in contrary to the findings in our study. ${ }^{14}$

Tonic seizures were most common $(60.9 \%)$ followed by subtle $(39.1 \%)$ in preterm neonates in our study, followed by subtle $(40.5 \%)$ and focal clonic $(14.3 \%)$, multifocal clonic $(13 \%)$, clonic $(11.9 \%)$ and the least was myoclonic $(2.4 \%)$ in full-term babies which correlates with findings of Volpe in his study and are contrary to findings of Cornblath and Schwartz and Scher et al. .,1,15,16 $^{-1}$

Early onset of seizures is a predictor of bad prognosis in general, onset within 48 hours of birth indicates a grave 
prognosis, whereas seizures starting after $4^{\text {th }}$ day of life have relatively better prognosis. In the present study onset of seizures $<12$ hours had an outcome of death 2 (18.2\%), 24-48 hours-death 2 (14.3\%), 2-6 days - death 3 $(12.5 \%)$ and $>7$ days - death $3(100 \%)$. These findings are on par with findings of Clancy and Legido, Ortibus et al. ${ }^{17,18}$

Hypoxic-ischemic encephalopathy is the most common cause of neonatal seizures with $81.5 \%$ in stage-II HIE and $18.5 \%$ in stage-III contributing to $75-85 \%$. which coincides with findings in studies of David Evans and Malcolm Levene, Bergman et al and Leviton and Nelson. ${ }^{19-21,13}$

\section{CONCLUSION}

Neonatal seizures are common and may be the first manifestation of neurological dysfunction after a variety of insults. Seizures may interfere with cardio-respiratory function and nutrition and may have detrimental effects on cerebral development. Global cerebral hypoxiaischemia is the most common etiology of neonatal seizures, followed by intracranial bleed, hypoglycemia, septicemia, hypocalcemia, BE, CNS malformations. ${ }^{22}$

Seizure etiology, early onset of seizures, prolonged, repetitive and the need for multiple anticonvulsants to control seizure activity are always associated with an increased mortality.

Funding: No funding sources Conflict of interest: None declared

Ethical approval: The study was approved by the Institutional Ethics Committee

\section{REFERENCES}

1. Gopakumar H, Putheenveettil V. Neonatal seizures. In: Gupte S (ed): RAP Special New Delhi: Jaypee. 2010;21:290-312.

2. Holmes GL, Khazipov R, Ben-Ari Y. New concepts in neonatal seizures. Neuro Report. 2002;13:3-8.

3. Holmes GL. Effects of seizures on brain development: Lessons from the laboratory. Pediatr Neurol. 2005;33:1-11.

4. Rennie JM, Boylan GB. Neonatal seizures and their treatment. Curr Opin Neurol. 2003;16:177-81.

5. Bassan H, Bental Y, Shany E, Berger I, Froom P, Levi L, et al Neonatal seizures: dilemmas in workup and management. Pediatr Neurol. 2008;38:415-21.

6. Zupanc ML. Neonatal seizures. Pediatr Clin N Am. 2004;51:961-78.
7. Volpe JJ. Neonatal seizures: Current concepts and revised classification. Pediatrics. 1989;84:422-8.

8. Scher MS, Aso K, Berggarly ME. Electrographic seizures in preterm and full-term neonates: Clinical correlates, associated brain lesions, and risk for neurologic sequelae. Pediatrics. 1993;91:128-34.

9. Upadhyay A, Aggarwal R, Deorari AK, Paul VK. Seizures in the newborn. Indian $\mathrm{J}$ Pediatr. 2001;68:967-71.

10. Mizrahi EM, Kellaway P. Characterization and classification of neonatal seizures. Neurology. 1987;37:1837-44.

11. Gupta A, Talukdar B, Kumar A. Clinicoetiological and EEG profile of Neonatal Seizures. Indian J Pediatr. 2007;74(1):33-7.

12. Mizrahi EM. Neonatal seizures: Problems in diagnosis and classification. Epilepsia. 1987;28:46.

13. Evan D, Lenene M, Danner R. Neonatal seizures. Arch Dis Child Fetal Neonatal Ed. 1998;78:70-5.

14. Rose AL, Lombroso CT. Neonatal seizure states. A study of clinical, pathological, and electroencephalographic features in 137 full-term babies with a long-term follow-up. Pediatr. 1970;45:404-25.

15. Cornblath M, Schwartz R. Disorders of carbohydrate metabolism in infancy. Philadelphia, WB Saunders; 1966.

16. Scher MS. Seizures in the newborn infant diagnosis, treatment and outcome. Clin Perinatol. 1997;24:735-71.

17. Legido A, Clancy RR, Berman PH. Neurologic outcome after electroencephalographically proven neonatal seizures. Pediatrics. 1991;88:583-96.

18. Ortibus EL, Sum JM, Hahn JS: Predictive value of EEG for outcome and epilepsy following neonatal seizures. Electroencephalogr Clin Neurophysiol 1996;98:175-85.

19. Yldz. Evaluation of etiologic and prognostic factors in neonatal convulsions. Pediatr Neurol. 2012;47(3):186-92.

20. Bergman I, Painter MJ, Hirsch RP. Outcome in neonates with convulsions treated in an intensive care unit. Ann Neurol. 1983;14:642-7.

21. Nelson KB, Leviton A. How much of neonatal encephalopathy is due to birth asphyxia? Am J Dis Child. 1991;145:1325-31.

22. Heljic S, Uzicanin S, Catibusic F, Zubcevic S Predictors of Mortality in Neonates with Seizures; a Prospective Cohort Study. Med Arch. 2016;70(3):182-5.

Cite this article as: Nagaram PP, Piduru P, Munagal VK. Neonatal seizures and outcome in a NICU of a tertiary care hospital of Andhra Pradesh-an two year study. Int J Contemp Pediatr 2017;4:1004-7. 